\title{
Impact of Employee Engagement on Performance
}

\author{
Anjum Tanwar
}

\author{
Assistant Professor, IITM, New Delhi, India
}

\begin{abstract}
Employee engagement is a vast concept and has a wide area of interpretation and thus each organisation interprets the meaning of employee engagement on its own terms, knowledge, and culture. Employee engagement is a relationship between the employee and the enterprise, an engaged employee is the one who is entirely engrossed in and ardent about their work and so takes positive steps to further the organisation's prestige and interests. The construct employee engagement is built on the foundation of concepts like organisation citizenship behaviour, employee commitment, and job satisfaction. Though it relates to and besets these concepts but employee engagement is broader in scope. In today's scenario organisations have started looking out for ways more stronger than only monetary incentives to keep employees involved and work towards goals, hence comes the role of employee engagement which helps the employees realise they are a part of the organisation and thus employees are emotionally connected to their organization and highly involved in their job with a great enthusiasm for the success of their employer, going an extra mile beyond the employment contractual agreement assuming all their efforts leads to the growth of what already belongs to them. Since Employee engagement is a fairly novel concept thus a lot of measurement metrics are not present to find out direct relationship between employee engagement and its impact on the performance of employees thus the purpose of this paper is to find out an Impact of employee engagement on the performance of the employees.
\end{abstract}

Keywords- Organisation Citizenship Behaviour, Employee Commitment, Employee Engagement, Job Assignment, Non-Financial motivational factors.

\section{INTRODUCTION}

Employee engagement is a part of employee motivation activity which is assumed to lead the employees to enthusiastic work dealing and achieving organisational objectives Kahn (1990 p. 694). It is absolutely important to keep the employees motivated to work and complete their jobs with utmost dedication and reach the goals. As employee engagement is a novel concept thus studies indicate that there is no single description regarding engagement of employees. There is no general or universally accepted approach to describe the terminology employee engagement. It has various aspects to it like a relationship between employee and organisation, belongingness of employees towards their work and the employer, leadership consideration of workers is the main area of consideration for carrying out the work effectively and efficiently. It is an era of growth the organisations are leaving no stone unturned in aspects of investment and cost-cutting which will give them a competitive edge. According to the recent studies, one of the most important factors considered for development in recent times is the "soft core" of the organisation which is Human resources and thus emerges the concept of employee engagement. Ordinarily the organisations to emphasise the importance financial factors in the development process like dealing in earnings and accounting returns, financial benefits are considered to be the true reflectors of the organisational growth and development ignoring the fact that these benefits root down to the performance by employees and thus it is of utmost importance to keep the employees satisfied for achieving a long term benefits.

It can, however, be very difficult to choose the metrics by which the organisational performance is measured as there can be a serious turmoil between the financial and non-financial factors. Studies indicated that emphasis on non-financial factors will lead to the growth of financial factors. Thus an organisation striving to be financially strong will have to first take into account the nonfinancial factors which include employee engagement, employee empowerment, employee satisfaction, and employee motivation.

The era of cut throat competition and constant technology change has led the organisations to believe that one of the paramount domains of acquiring competitive edge is competent, rare, loyal and committed workforce. The researchers are also digging the areas other than financial factors to give the organisation a competitive edge and to improve the quality of the products or services. The concepts like TQM (Total Quality Management), Business process re-engineering are the result of shifting the area of research from the financial perspective of development to non-financial areas being it the improvement in operations, processes or making 
strategies to keep employees engaged to perform better and be benefitted in the long term. As the sophistication of technology continues to educe, it becomes difficult for the manager to keep up the training and employing new workforce thus, if the employees are adequately engaged they will learn and be updated by themselves to keep up the performance.

Researchers of human resource management have long been bothered by the question of how the management of human resource effectively and efficiently can lead to improved performance, (Huselid 1995) and thus came into existence SHRM (strategic human resource management), Delbridge and Keenoy 2010).

Any action of improvement taken by management can't be conducive without wilful involvement and engagement of employees. Employee engagement is a broad concept. This research restricts itself to understand the concepts of employee engagement based on recent literature and its impact on the performance of employees. It has three main sections. Primarily, the article analyses the maturation of the concept, its meaning and how it is distinct from the previous concepts such as employee involvement, Commitment, Organizational Citizenship Behaviour (OCB) and job satisfaction (Robinson, Perryman and Hayday, 2004; Rafferty et al., 2005. Secondly, the research reviews the factors influencing engagement. Finally, it examines the impact of employee engagement on organizational performance index or business outcomes such as customer satisfaction, productivity, company growth, profitability, lower turnover, and absenteeism.

\section{LITERATURE REVIEW}

2.1 M. Sandhya Sridevi . ( 2010) suggests that as the concept of employee engagement has not gathered a lot a fame and is yet to be discovered properly thus, there are many definitions that rule the concept of employee engagement, this is to say that there is no one universally accepted definition on which the ground rules could be set. The organisations are trying their best to incorporate employee engagement according to the way they think is fit or workable as unlike concepts which are academically proven (TQM, Lean Management, and Business Process Reengineering)

No general guidelines are given. The author has also tried to explain the difference between various concepts which has similar construct as the employee engagement. The constructs like Commitment, Organisation Citizenship Behaviour are based on the same lines as employee engagement, but employee engagement is much more colossal than these concepts, i.e. these concepts come under the scope of employee engagement. Employee engagement as discovered by the author is much more interactive and a two-way exchange process of efforts between employer and employee. Most studies manifest that the feeling of being valued by management, management's interest in employee's well- being, giving more opportunity for employee's growth are top drivers of employee engagement. Not much importance was given to the pay as incentives in the studies undertaken by the author but it is possible because all the organisations contributing to the study belonged to developed countries, the survey may vary in underdeveloped countries. So the author mainly focuses on the evolution, meaning, and definition of the employee engagement concept.

2.2 Jamie A Gruman., Alan M. Saks. (2011)

The constant economic challenges have led organisations to undertake improvements in performance management, Buchner (2007). This paper suggests that achieving enhanced performance through performance management technique is best possible by obtaining employee engagement. It states that performance management if properly applied will help to cultivate and sustain a high level of employee engagement which in turn leads to higher level of performance. The main aim of this paper is to present various techniques of effective application of performance management which will lead to employee engagement furthering the performance of the organisation. The paper talks about the link between the performance management and employee engagement i.e. various methods of performance management have been brought out which include more interactive management of performance by the employer. The performance management should be such that it involves the employees the feedback should be appropriately communicated back so that employees are part of the performance management as a whole. Various performance management techniques are scrutinized in this paper to discover such performance management methods which lead to employee satisfaction, commitment, and high morale all these positive factors are a result of those performance management systems which are the result of systems involving a higher level of employee engagement.

The paper clearly states that effective application of appropriate performance management system leads to employee engagement which further leads to higher performance.

2.3PalukuKazimoto. (2016) - The author suggests that there is a strong relationship between job satisfaction, fair rewards, availability of right tools and appropriate resources to complete the work and employee engagement. The paper talks about the strong link between the job assignment and employee engagement. The results reveal that the managers need to focus on the 
reducing work stress improving motivation and work environment to increase the employee engagement. When an employee has been assigned the job properly the employees will deal with less stress confusion and be able to take up other responsibilities in the organisation which will lead to higher employee engagement. Higher employee engagement will result in positive factors like employee motivation and commitment towards the works and employer thus leading to greater performance. The study also focuses on how non-financial factors leading to higher performance are ignored and mainly financial factors are given the highest priority. Which is a half won a battle against the measurement of performance and factors behind a high performance. The financial and nonfinancial factors should be considered while measuring the performance for the longevity of organisations.

\subsection{Harvard business review (2013)}

Employee engagement has become a high business priority among senior executives.in the rapidly growing economy and cutthroat competition, the management realizes that having highly engaged employees is utmost necessary for improving the performance and bringing out innovative, creative ideas, increasing productivity and at the same time reducing the cost of retention, acquisition in a competitive labour market. The study has divided the organisations into high prioritizers and low prioritizers, high prioritizers are those who give high priority to employee engagement in organisations and low prioritizers are those who place employee engagement at a lower level in the organisation. The top management reviews when analysed resulted in an assumption of having high employee engagement in their organisation but the middle-level management to whom the employees are more proximal have a view of low employee engagement in their organisation. This shows that senior executives in spite of being in favour and understanding the importance of employee engagement are not able to incorporate the same in their organisation.

The study also reveals that among the factors which are most likely to bring success in the organisation are -High level of customer service (80\%), High level of employee engagement (71\%) Strong executive leadership (71\%), Effective communication (73\%), Efficient productivity (68\%), Ability to innovate $(59 \%)$ and Strong sales and marketing capabilities (58\%). Thus, employee engagement holding $71 \%$ importance in the success of an enterprise being the $3 \mathrm{rd}$ most important factor in the success of the organisation. The study also suggests some best practices in tying the employee engagement activities to business performance. The author measures the impact of employee engagement on customer satisfaction and employee satisfaction.

\section{OBJECTIVE}

Previous studies have reviewed the concept of employee engagement how it evolved and various issues related to employee engagement. Studies explained how employee engagement has led to the satisfaction of employee and customers. It scrutinizes the relationship of the employee engagement program with performance management and job assignment. This paper clearly studies how the positive aspects of employee engagement leads to the rippling down effect on overall performance and the importance of non-financial factors in motivating the employees and building higher levels of employee engagement. This paper also more clearly states the difference between the concepts relating to employee engagement and what employee engagement actually stands for.

\section{REPORT \\ EMPLOYEE ENGAGEMENT}

Employee engagement being a novel concept has no universally accepted definition and thus, the definition varies with the difference in intellectual processes (Rafferty, Maben, West and Robinson, 2005; Melcrum Publishing, 2005; Ellis and Sorensen, 2007). Employee engagement is a relationship between the employee and the enterprise, an engaged employee is the one who is entirely engrossed in and ardent about their work and so takes positive steps to further the organisation's prestige and interests. Engagement of employees with the organisation is how employees feel about their senior executives, the trust that the employees have in the values policies, fairness and the confidence in organisational leadership.

The concept employee engagement originates from two concepts organisation citizenship behaviour (OCB) and employee Commitment, (Robinson, Perryman, and Hayday, 2004; Rafferty et al., 2005).employee engagement has a resemblance to the above-stated constructs, but is different from these and overlaps these constructs in meaning and scope i.e. it is a wider concept. Rafferty et al (2005) differentiate employee engagement and the two previous constructs- OCB and Commitment; on the ground that engagement clearly demonstrates that it is a two-way mutual process between the employee and the organization. Engagement is an exchange of efforts between the employer and the employees to achieve organisational objectives and further the performance of the organisation. OCB occurs in employees when they feel they are a part of the organisation follow its culture and values respect its leaders and maintain the work environment and conditions. Employee commitment is when the employees are loyal to the organisation; they 
understand their work and do not easily switch their jobs. Job satisfaction is when the employees contend with their jobs and the job fulfills all their wants and desire, they feel perfectly fit in their job, it is the degree to which one feel positively or negatively about their jobs. Employee involvement is when the employees are encouraged to take part in the decision making, improvement and change activities. Employees are encouraged and an environment is created to make the employees take part in assignments beyond their work.

Employee engagement, on the other hand, incorporates all these activities and is much more interactive as it is a twoway process, when the employees are effectively engaged they trust the policies and have confidence in the values vision and mission of the organisation, they stay put in the jobs they are and rarely seek job change, they are motivated and enthusiastic about their work and do not hitch in taking extra work or duties. They are not encouraged by any outside force to do the tasks and duties beyond what is assigned to them as they voluntarily take it up. They do participate in the decision-making process as they are passionate about their work and feel a profound connection with their organisation.

\section{Factors influencing employee engagement}

Many researchers have diagnosed the field of employee engagement to determine the factors that will increase the employee engagement in the organisation. The employees are willing and enthusiastic to work where they find meaning. The workplace is the prime spot where employer and employee can come closer together for the benefit of both, the employee feels a sense of community, a comfortable space for themselves and finds opportunities to contribute to the growth of the organisation, Penna (2007). A new model of engagement like the Maslow's need hierarchy has also been developed by the researchers where the lowest level being the basic need like pay and benefits most need once satisfied then the employee looks at the higher needs to be fulfilled which are opportunities, the possibility of promotion and leadership. The final level of this hierarchy is aligning personal values with the values of the firm and discovering a common objective and a sense of connection. There must be more opportunities to grow and a strong employee-employer relationship for initiating employee engagement, The BlessingWhite (2006). According to Development Dimensions International (DDI, 2005), there must be 5 essential factors to create a highly engaged workforce, them being 1. Align efforts with strategy 2. Empower 3. Promote and encourage teamwork 4. Provide opportunities to grow and develop 5. Recognize the efforts.

There must be senior management's support and interest in employee well-being, decision-making authority and challenging work for higher employee engagement, Penna (2007). The sense of feeling involved and valued, the extents to which employees are able to voice their opinions, the opportunities provided to the employees to develop are major factors driving employee engagement in an organisation. The social and physical settings in an organisation i.e. the employees having a network of informal groups are more engaged than those working in a purely formal setting. The organisations which keep the employees more informed about what is going on in the financial and operational front would have highly engaged employees than those who do not. Thus it is rightly said, "as a social being, human resource is not motivated by money alone." Buckingham and Coffman (2005). Financial incentives are not the only factors to keep their employees engaged but there are many other important non-financial incentives which lead to higher levels of engagement.

\section{Impact of employee engagement on performance}

Organisations today are inclining towards employee engagement and it is getting popularity all over the world thus, the question that arises now is what is the benefit of employee engagement is its only employee satisfaction and keeping the morale of employees high or does it serve other financial benefits also? Because surely resources are invested in obtaining high levels of employee engagement hence, there must be performance benefits to make the construct worthwhile.

Studies show an affirmative correlation between employee engagement and higher performance outcomes: productivity, customer loyalty and safety, employee retention, profitability, customer satisfaction and employee satisfaction lower rates of employee turnover and absenteeism. The engaged employees are most likely to have low errors in performing a task which disengaged employees perform with high errors (Gonring, 2008)

Employee engagement and performance outcomes are networked together, higher the employee engagement higher the feeling of belongingness, enthusiasm, passion, work knowledge, better employer-employee relations which leads to less confusion, less conflicts , less absenteeism, less employee turnover more role knowledge, which leads to effectiveness and efficiency in work and leading the employees to take up extra work or duties to further the performance and reputation of the organisation which expedite the process of advancement of the organisation. Indeed, organisations are approximately twice as likely to be successful if they are above average in employee engagement (Harter et al., 2009).

There is a positive link between engagement and employee satisfaction, (Coffman, 2000; Ellis and Sorensen, 2007; Towers Perrin Talent Report, 2003; 
Hewitt Associates, 2004; Heintzman and Marson, 2005; Coffman and Gonzalez-Molina, 2002). When the employees are highly engaged with an organisation the concern shifts from working for a fixed period time and earning a fixed amount of salary to being able to reach highest capabilities possible to achieve mutual goals. Employees are satisfied when they realise that they are working at the right job for the right compensation, have the opportunities to grow and are valued in the organisation. Employee engagement provides for all of the above-mentioned benefits thus leading to employee satisfaction. When the employees feel empowered in their job and feel satisfied there are rare chances that they seek jobs outside which improves the retention the ratio.

Highly engaged employees lead to customer satisfaction (Harvard business review, 2013). Engaged employees are more empowered and have the authority to take decisions thus they feel the pressure to perform and excel there are no instructions that guide them which makes them the boss of the situation and the boss always thinks for the best. The employees have the appropriate knowledge and also are passionate enough to help the customers and close the deal with a happy note which makes them go an extra mile if need be to serve to the customers.

Engaged employees exhibit some common traits which help to obtain higher performance--1.The employees feel proud to be associated with the organisation and have an acute desire to be the member of the organisation despite the opportunities available outside the organisation. 2. The employee does not hesitate in exerting extra efforts, time and initiative to devote to the success of an organisation. 3. The employee has positive feelings about the organisation and advocates for it to another making way for potential employees and customers. ( Baumruk and Gorman, 2006)

Disengaged employees are the one who sleepwalks through their work day meaning they do not put their whole heart and soul to the work they just do it for the sake of it, they do not only keeps the performance stagnant or probably lower it down but also are burden for the organisation as they create chaos and confusion in the firm. They waste their talent on various activities that may not be of much importance. They are settling, which means that they are not fully engaged and not dissatisfied enough to leave the organisation, which mean that they settle for a fixed amount of salary thy are getting and put no efforts to further the performance of the organisation.

\section{CONCLUSION}

Employee engagement being new to the academic sphere has not yet gained a lot of exposure by researchers and thus is yet to reach heights of academic excellence. Though it has not yet been taken up by a lot a researchers but it has become a popular concept in the corporate sphere. Due to rapid economic development and dynamism of technology the competition among the firms is getting fierce with every passing day. Dealing with such fierce competition by only taking in account the financial factors of improving performance will not suffice and therefore the organisations are moving toward the non-financial factors of performance development one of them being employee engagement. Employee engagement is the most important factor to be considered to keep the employees motivated, enthusiastic and completely absorbed in their work. It can also be concluded that employee engagement not only is helpful in keeping the employees satisfied and motivated towards giving their best efforts and to go an extra mile for improving the performance of the organisation but it is also woven together with other positive results in performance like improvement in productivity, profitability, customer satisfaction and customer loyalty lower employee turnover and absenteeism. Employee engagement has various drivers like empowering the employees, providing full information, support from the top management, aligning efforts with strategy etc. which should be kept in mind by the organisation while planning to engage their employees effectively.

\section{REFERENCES}

[1] Sridevi M. Sandhya. (2010), "Employee Engagement: The Key to Improving Performance", International Journal of Business and Management Vol. 5, No. 12, 89-96.

[2] Gruman A. Jamie and Saks M. Alan.(2011),"Performance management and employee engagement", Human Resource Management Review 21,123-136.

[3] KazimotoPaluku (2016)," Employee Engagement and Organizational Performance of Retails Enterprises", American Journal of Industrial and Business Management, 516-525.

[4] Kahn, W.A. (1990),"Psychological conditions of personal engagement and disengagement at wor", Academy of Management Journal, 33, 692-724.

[5] Huselid, M.A. (1995), "The Impact of Human Resource Management Practices on Turnover, Productivity, and Corporate Financial Performance" Academy of Management Journal, 38, 635-672.

[6] Baumruk R. and Gorman B. (2006),"Why managers are crucial to increasing engagement" Melcrum Publishing.

[7] Delbridge, R., and Keenoy, T. (2010),"Beyond Managerialism?" The International Journal of Human Resource Management, 21, 799-817. 
[8] Blessing White.(2006),"Employee Engagement Report 2006 BlessingWhite", Inc. Princeton, New Jersey. [Online] Available: www.blessingwhite.com (November 15, 2008)

[9] Gonring, M.P. (2008),"Customer loyalty and employee engagement: an alignment for value." The Journal of Business Strategy, 29(4), 29-40.

[10] Harter, J. K., Schmidt, F. L., Killham, E. A. \& Agrawal, S., T. L. (2009). Q12® Meta-Analysis: The Relationship Between Engagement at Work and Organisational Outcomes.

[11] Rafferty A. M., Maben J., West E., and Robinson D. (2005."What makes a good employer?"Issue Paper 3 International Council of Nurses Geneva.

[12]Ellis C. M., and Sorensen A. (2007)," Assessing Employee Engagement: The Key to Improving Productivity Perspectives", vol .15, Issue 1 The Segal Group, Inc.

[13] Hayday S. (2004), The Drivers of Employee Engagement Report 408, Institute for Employment Studies, UK

[14] Melcrum publishing. (2005),"Employee engagement: How to build a high-performance workforce". An independent Melcrum Research Report Executive Summary.

[15]Penna (2007).Meaning at Work Research Report. [Online] Available: http:// www. e-penna.com/ newsopinion/research.aspx (November10, 2008)

[16] Development Dimensions International.(2005). (Predicting Employee Engagement MRKSRR121005 Development Dimensions International, Inc., MMV. 